\title{
Desprovincializar as universidades europeias
}

Déprovincialiser les universités européennes

Deprovincializing European universities

\author{
Caroline Rolland-Diamond, Capucine Boidin, James Cohen e Ramon \\ Grosfoguel
}

\section{(2) OpenEdition}

\section{Journals}

Edição electrónica

URL: https://journals.openedition.org/ideas/3048

DOI: $10.4000 /$ ideas.3048

ISSN: 1950-5701

Este artigo é uma tradução de:

Déprovincialiser les universités européennes - URL : https://journals.openedition.org/ideas/278 [fr]

Outra(s) tradução(ões) deste artigo:

Deprovincializing European universities - URL : https://journals.openedition.org/ideas/2292 [en]

Desprovincializar las universidades europeas - URL : https://journals.openedition.org/ideas/3053 [es]

\section{Editora}

Institut des Amériques

Refêrencia eletrónica

Caroline Rolland-Diamond, Capucine Boidin, James Cohen e Ramon Grosfoguel, «Desprovincializar as universidades europeias», IdeAs [Online], 2 | 2012, posto online no dia 26 julho 2018, consultado o 19 outubro 2022. URL: http://journals.openedition.org/ideas/3048 ; DOI: https://doi.org/10.4000/ideas. 3048

Este documento foi criado de forma automática no dia 19 outubro 2022. 


\title{
Desprovincializar as universidades europeias
}

\author{
Déprovincialiser les universités européennes \\ Deprovincializing European universities
} Caroline Rolland-Diamond, Capucine Boidin, James Cohen e Ramon
Grosfoguel

\section{As universidades europeias numa encruzilhada}

1 A classificação de Shanghai publicada em 2003 feriu profundamente o orgulho francês ao rebaixar suas universidades e grandes escolas no final da tabela de classificação, distante das universidades das megalópoles norte-americanas, britânicas e japonesas. Milhares de críticas foram formuladas em relação a esta classificação. Provavelmente, a mais importante é a vantagem comparativa da qual desfrutam as publicações em língua inglesa na competição internacional e a dificuldade de hierarquizar as universidades no domínio das ciências humanas e sociais. Porém, a análise atualizada de várias classificações mundiais, realizada por Hervé Théry para nossa rúbrica chamada "Eclairages" ("Destaques"), nos incentiva a descentrar nossa visão: "Para as quatro classificações obtidas, a concentração das universidades classificadas em algumas regiões do mundo é tal que foi preciso acrescentar ao planisfério três zooms para detalhar a situação dos Estados Unidos, da Europa e do Japão." Este artigo convida os leitores francófonos a adotar uma visão mais ampla e a preocupar-se não só pelo único "declínio" ou pela "incomparabilidade" do modelo francês, mas também pelas desigualdades mundiais ${ }^{1}$; é preciso observar, em particular, o desequilíbrio entre as universidades norte e sul-americanas, mesmo que as universidades brasileiras, mexicanas, argentinas e chilenas apareçam em algumas classificações² ${ }^{2}$.

2 Seria preciso utilizar as classificações como o sal, evitando o excesso de zelo ou a rejeição estéril para retomar a expressão de Boaventura de Sousa, cujos leitores encontrarão aqui algumas reflexões e proposições fortes para as universidades europeias na seção "Eclairages" deste número. Pensar a situação das universidades 
europeias através das experiências americanas é o objetivo geral deste artigo. A influência do modelo americano de ensino superior começou a ter peso na América Latina, antes de chegar à Europa. A liberalização do mercado do ensino superior, a multiplicação das agências de avaliação, mas também a criação de instituições universitárias especializadas para algumas minorias, é implementada na América latina desde os anos 1990. O artigo de Manuela Boatca neste dossiê ilustra precisamente a maneira pela qual as "iniciativas de excelência" na Alemanha são pensadas como um meio para recuperar o novo ocidente, o modelo norte-americano de ensino superior. A sensação de ter que "recuperar" um atraso é portanto muito forte dentro do sistema universitário europeu, mesmo que o ponto de partida para a criação deste espaço comum de ensino superior tenha outras raízes.

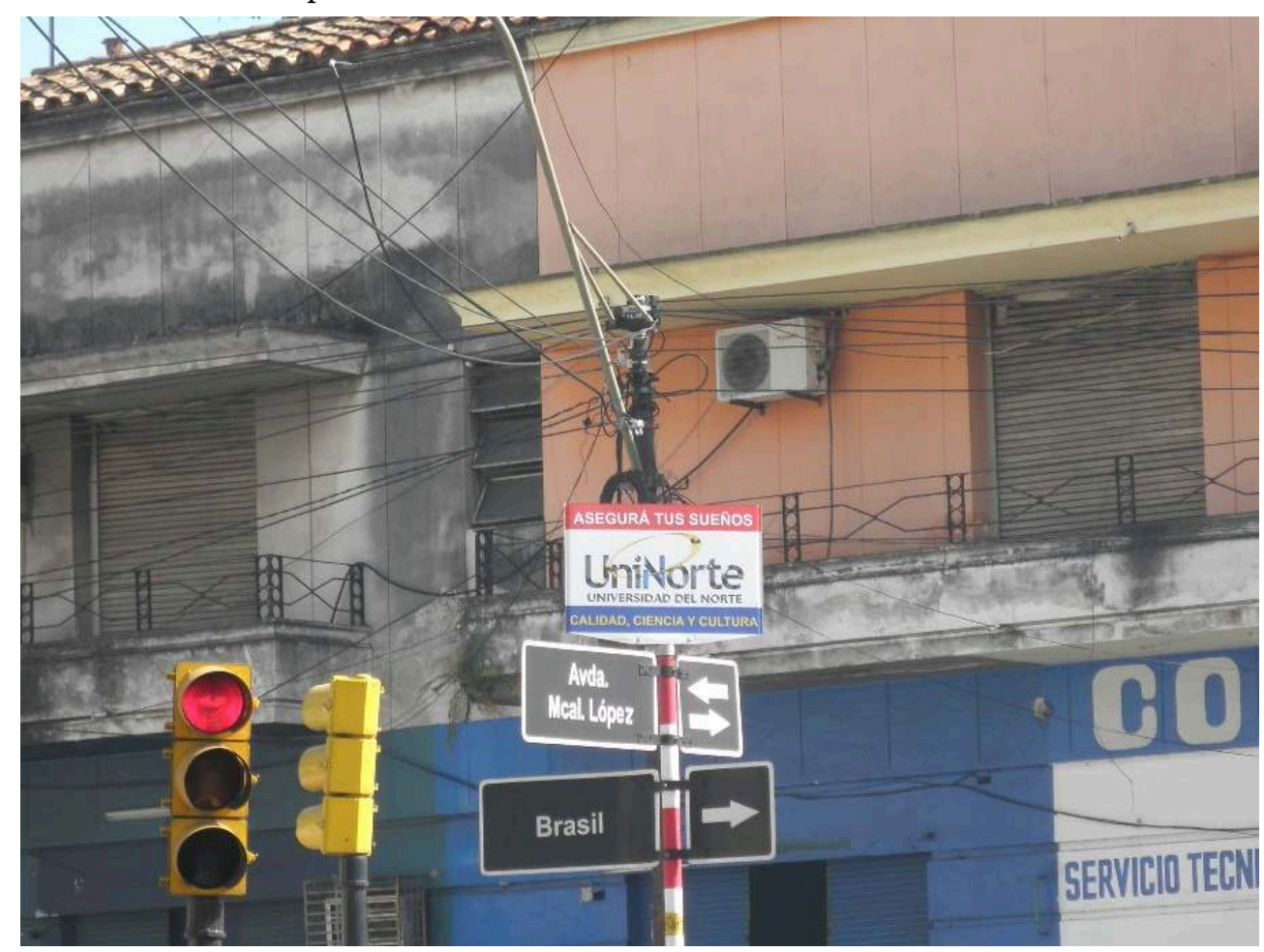

Publicidade para a Uninorte, Asunción

Uma publicidade onipresente na cidade de Assunção pela UNINORTE, uma universidade privada: "Lembre-se de realizar os seus sonhos", Universidade do Norte, Qualidade, Ciência e Cultura. O imperativo é acentuado segundo a pronúncia paraguaia, influenciada pela língua guarani: «Asegurá ». Foto: C. Boidin, Paraguai, 2011

Lembremos que o projeto de criar um espaço europeu de ensino superior foi lançado na Sorbonne em 19983: "A Europa que nós construímos não é somente aquela do Euro, dos bancos e da economia; ela também deve ser uma Europa do saber." Este processo foi lançado oficialmente em 1999, em Bolonha, com a assinatura de 29 países. Mas ainda foi acrescentado, na declaração da Bolonha, um objetivo ausente em 1998: "a cooperação europeia no controle de qualidade." O que significam estas duas palavras juntas, "controle e qualidade?" "No ensino superior, o controle de qualidade remete às políticas, aos procedimentos e às práticas concebidas a fim de garantir, manter ou melhorar a qualidade tal como se entende num contexto especifico". ${ }^{4}$ Neste dispositivo, a autonomia e a responsabilidade financeira dos estabelecimentos, junto com o caráter externo da avaliação, são os dois pilares que permitem "dar confiança" aos diferentes 
parceiros quanto à qualidade de seus estabelecimentos universitários. Em 2007, a criação do Registro europeu para a garantia da qualidade (EQAR) precipitou a criação de estruturas nacionais de avaliação da qualidade nas universidades: Na França, por exemplo, a AERES (Agência de Avaliação do Ensino e de Pesquisa).

4 As universidades foram então concebidas como sendo governáveis, da mesma maneira que as empresas: pelo método do benchmarking (a focalização de objetivos concretos a serem atingidos - com urgência), analisado por Isabelle $\mathrm{Bruno}^{5}$, os indivíduos e as organizações são obrigados a se submeter a estes objetivos e entram em concorrência uns com os outros. O financiamento "de iniciativas de excelência" ou, para que fique mais claro, o financiamento "orientado" de instituições e de programas, consta desta lógica de competição. A cooperação pode ser difícil a concretizar-se e qualquer reflexão profunda resulta impossível: cria-se uma corrida para obter financiamentos, conseguir os objetivos e receber as entregas de relatórios, e tudo isso monopoliza todas as energias e preenche todas as agendas das instituições de ensino superior. Conforme resume Boaventura de Sousa:

"In a few decades the university went from producing knowledge and professionals for the market, to becoming itself a market, the market of tertiary education, and finally, at least according to powerful visionaries, to being run like a market organization, a business organization".

O segundo e último grande objetivo acrescentado ao projeto inicial que foi delineado na Sorbonne - aquele da « dimensão social do ensino superior » - foi claramente definido apenas em 2007 pelo Comunicado de Londres que declara, finalmente, que "os corpos discentes que têm acesso ao ensino superior, e que fizeram e completaram seus estudos, deveriam refletir, em todos os níveis, a diversidade de nossas populações" 6 . Ora, neste quesito, em 2010, considerando os critérios de boa governança (objetivos calculados e por tanto, mensuráveis), o balanço comercial é mais decepcionante do que para a criação de um quadro comum de referência ${ }^{7}$ ou para a implantação do controle de qualidade:

“Pouquíssimos países fixaram objetivos quantificados específicos para melhorar a participação dos grupos subrepresentados no ensino superior, e somente a metade dos países que assinaram a declaração de Bolonha controla de maneira sistemática sua participação. As medidas nacionais mais frequentes para ampliar a participação consistem em obter um apoio financeiro orientado e em criar filiais de acesso e/ou procedimentos de admissão paralelos. (...) Nos países signatários dos processos da Bolonha, a sub-representação é frequentemente ligada à origem socioeconômica ou ao nível de estudos dos parentes, ao estatuto de minoria ou a alguma deficiência. (...) As diferentes estratégias adotadas para identificar os grupos subrepresentados mostram que em muitos casos trata-se de situações muito sensíveis, o que, na prática, dificulta as possibilidades de estabelecer comparações pan-europeias." (salientamos)

6 Resumindo, são implementados financiamentos orientados para alguns membros de categorias definidas, a fim de que possam ingressarem em algumas instituições de elites suscetíveis de ser competitivas a nível internacional - fazendo com que, ao mesmo tempo, os investimentos nas demais instituições diminuam, o que reforça os processos de marginalização, que deveriam ter sido corrigidos por esta política. A panaceia seria uma universidade de elites "diversificadas", graças às filiais paralelas de acesso. 0 objetivo determinado é refletir sobre a diversidade da população. Mas não se trata de promover uma igualdade de oportunidades para todos. 
7 Finalmente, desde 1999, novos processos de racionalização são estimulados no centro das universidades europeias: a multiplicação de critérios quantificados e "avaliáveis" para medir, classificar e financiar a atividade das universidades, tanto no que diz respeito aos ensinos quanto para as publicações; a pesquisa da "diversidade" como critério de justiça social. Dois dispositivos, de natureza diferente, que são constitutivos do funcionamento do modelo norteamericano de ensino superior, mas que no fundo resultam de uma história particular.

\section{Além do modelo ou do contraponto: o sistema de ensino superior americano em perspectiva}

8 Modelo ou contraponto repelente, o sistema de ensino superior americano é, na realidade, quase sempre mal conhecido. Uma recapitulação de suas características, na abertura deste número, será portanto muito útil. Concebidos durante o período da América colonial, os primeiros colégios que, mais tarde, se tornarão, por motvio de sua antiguidade venerável, as universidades ditas de Ivy League, são estabelecimentos privados. Sua função consiste, inicialmente, em formar as elites políticas e espirituais das colônias britânicas. A divisão territorial em treze colônias relativamente autônomas explica a multiplicação destas instituições que, no modelo de Oxford e Cambridge, desenvolvem um sistema de campus residencial para seus estudantes. Após a independência, a jovem República reconhece imediatamente (com a Ordenança do Noroeste de 1785) a necessidade social de dotar-se de instituições públicas de ensino em cada um dos novos Estados criados. Nesta época, trata-se, acima de tudo, de desenvolver um sistema de escolas públicas elementares; antes de estender-se a todo o sistema de ensino, já é claramente formulado o duplo princípio da responsabilidade social dos Estados em assegurar uma escolaridade pública e em garantir sua utilidade para a sociedade. Rapidamente, implementa-se um sistema heterogêneo que integra tanto estabelecimentos completamente privados quanto estabelecimentos financiados pelo Estado onde eles se localizam. Isto é uma característica importante da educação nos Estados Unidos: ela é da responsabilidade dos Estados federados, não do Estado central.

O período que vai de 1785 a 1860 se caracteriza por uma inovação extrema e um forte consumismo, sem praticamente a menor supervisão ou regulamentação do Estado federal. Contudo, não é um período de caos, mas sim de multiplicação dos estabelecimentos e de inovação disciplinar. Em 1860, o número de estabelecimentos que conferem um diploma superior passa de 25 a 241. Além da criação de novos colleges, nesse período aparecem também outros tipos de instituições: as universidades propriamente ditas, as academias, os seminários, as escolas científicas, as escolas normais e os institutos. Paralelamente a este aumento dos estabelecimentos, o programa ensinado nos colleges é, em alguns casos, estendido, indo além das "artes liberais" (uma mistura de latim, de grego, de matemáticas, à qual se deve acrescentar a ciência, a filosofia, a história, assim como a composição e a literatura inglesas) para incluir a medicina, o direito, a engenharia, a ciência militar, o comércio, a teologia e a agricultura. 


\section{Nascimento das universidades públicas e das universidades reservadas às minorias (segunda metade do século XIX).} reforço da rede de estabelecimentos de ensino superior (com o nascimento de novas universidades públicas, de colleges e de universidades urbanas) e, por outro lado, a criação de instituições especialmente destinadas a permitir o acesso ao ensino superior de grupos excluídos até então: as mulheres ou os negros, por exemplo.

11 Para inicar esta nova fase, a lei Morrill de 1862 marca uma mudança importante: ela oficializa a criação do que chamamos os "land-grant colleges", ou seja, a criação de estabelecimentos de ensino superior sobre as terras concedidas a este fim pelo Estado federado. Graças a esta lei, as principais grandes universidades públicas do país nasceram. É uma das grandes etapas da democratização do ensino superior, hoje de fácil acesso (tanto em razão do custo pouco elevado dos estudos, quanto por causa da proximidade geográfica), para formar um grande número de rapazes e moças.

Enquanto os land-grant colleges e as universidades de Estado permitem aos jovens de inúmeras regiões rurais e de pequenas cidades ter acesso, finalmente, ao ensino superior, graças a sua proximidade geográfica e a seu custo razoável, um movimento similar aparece, nas grandes cidades, com a criação de colleges e universidades municipais. A tendência é, de fato, construir igualmente estabelecimentos públicos gratuitos ou quase gratuitos nos grandes centros urbanos ${ }^{8}$. 0 objetivo é responder às necessidades dos estudantes das cidades, oferecendo cursos inovadores de formação técnica industrial avançada ou de comércio, além dos cursos clássicos de "artes liberais". Pela primeira vez, este tipo de estabelecimento permite aos estudantes dos centros urbanos, que não possuem os recursos suficientes para matricular-se em tempo integral num college residencial (com campus), seguir os estudos e continuar ao mesmo tempo a morar com seus pais e/ou trabalhar, graças ao desenvolvimento dos cursos noturnos e aos dispositivos para os estudantes em tempo parcial. Relativamente baratos, estes colégios de proximidade rapidamente ocuparam um lugar único e indispensável no panorama do ensino superior americano.

$\mathrm{O}$ acesso das mulheres ao ensino superior se acelera após a Guerra de Secessão, uma vez que ele era limitado anteriormente a raros "seminários" ou "academias" abertas às mulheres. O processo de democratização tem duas formas: a criação de instituições específicas, os coordinate colleges, separadose no entanto ligados aos colleges masculinos (Radcliffe, por exemplo, é ligado a Harvard, Barnard a Columbia, ou ainda Newcomb a Tulane na Louisiana). Paralelamente, aparece um movimento de desenvolvimento da miscibilidade ${ }^{9}$. No final do século XIX, cerca de três quartos dos colleges e universidades do país são abertos para as mulheres, mesmo que o número de estudantes não represente mais do que $2,5 \%$ de todas as mulheres jovens americanas.

A luta das mulheres para acessar ao ensino superior coincide com o início do movimento de extensão das oportunidades educativas para os negros. Antes da Guerra de Secessão, apenas 29 estudantes negros puderam obter um diploma de ensino superior. Após a guerra, a maior parte das iniciativas são, num primeiro momento, de ordem beneficente ou religiosa. Aproximadamente no final do século, as fundações filantrópicas de grandes empresas e de benfeitores privados afortunados contribuem para o desenvolvimento dos colleges para negros. No total, 200 estabelecimentos privados ou religiosos destinados aos estudantes negros teriam sido criados nos anos 
1870 e 1880, mas na verdade a grande maioria deles eram apenas estabelecimentos que dispensavam um ensino secundário, remediando à falta de liceus para afroamericanos... sem contar que muitos estabelecimentos desapareceram rapidamente por falta de recursos. Além disso, perfila-se aqui um problema essencial relativo ao acesso dos negros ao ensino superior na América da segregação: a natureza do ensino dispensado e sua adaptação ao nível de estudos real dos jovens negros no final do século XIX.

15 A intenção original dos fundadores dos colleges negros é fornecer a estes estudantes uma educação idêntica àquela recebida pelos brancos, ou seja, uma educação fundada nas “artes liberais". Os líderes da comunidade negra acreditam que os futuros ministros, advogados, médicos, políticos e empresários negros do país devem adquirir, da mesma maneira que os brancos, tradições acadêmicas. Rejeitam a ideia de uma formação industrial e agrícola rudimentar como uma alternativa realista. Mas por culpa da quase ausência de escolas públicas primárias e secundárias para negros no Sul, o número de alunos permanece muito reduzido. Somente as universidades de Howard e Fisk oferecem realmente uma formação clássica, baseada nas artes liberais, de nível universitário. Diante de tal situação, muitos filantropos começam então a defender uma educação técnica mais adequada à realidade das oportunidades econômicas e sociais (bastante limitadas) disponíveis para os negros no Sul. O modelo a este respeito é o Instituto Tuskegee fundado pelo educador Booker T. Washington, no Alabama, em 1881. A filosofia desta instituição muito popular, com uma formação principalmente agrícola, inspira a criação de land-grant colleges para estudantes negros que se multiplicam no Sul, após a decisão da Suprema Corte americana "Plessy contra Ferguson", de 1896. Esta decisão formaliza a constitucionalidade da segregação, afirmando o princípio do "separate but equal "; desde então, para evitar aceitar negros em escolas e universidades públicas de seus Estados, os governos do Sul fazem tudo para criar colleges separados, mas dotados, em teoria, do mesmo tipo de recursos e de fundos distribuídos numa base "justa e equânime". No entanto, para os negros, a realidade da situação é uma realidade de separação e não de igualdade de tratamento, de tal forma que a democratização do ensino superior, até a Segunda Guerra Mundial, continua a ser, em grande parte, uma quimera.

Apesar destas limitações importantes, a democratização começa nessa época e não vai parar. Paralelamente a estes avanços, o ensino superior se reestrutura no final do século XIX, com o influência de dois fatores principais. Em primeiro lugar, a industrialização e o rápido desenvolvimento econômico do país dão aos saberes técnicos e científicos uma importância maior na sociedade. Cada vez mais, admite-se que a universidade tem que modernizar-se para atender às necessidades do mundo econômico. Em segundo lugar, é nessa época que o modelo universitário alemão, reconhecido como o melhor da Europa e voltado para a investigação científica, chega aos Estados Unidos. Esta popularidade do modelo alemão vai levar à criação, na educação superior americana, de uma nova instituição, "a universidade" de pesquisa. Nela, os professores são, antes de tudo, pesquisadores cuja independência deve ser preservada. Nesse modelo universitário, desenvolve-se o ensino de terceiro ciclo, tudo isto em oposição com o simples "college", voltado para o ensino e oferecendo uma formação de tipo undergraduate, sem desenvolver realmente uma atividade de pesquisa. Este novo tipo de instituição gera o aparecimento de novos estabelecimentos urbanos, como a Universidade Johns Hopkins, inteiramente criada neste modelo, que propõe unicamente cursos de nível graduate. Portanto, é desde o final do século XIX e o início do século XX que existem grandes universidades de pesquisa nos Estados Unidos, 
paralelamente a uma trama estreita de instituições especializadas no ensino undergraduate de artes liberais ou semiprofissional. Esta divisão do panorama do ensino superior americano continua até hoje.

\section{O impacto da G.I. Bill em 1945: massificação e avaliação}

17 A democratização do ensino superior continua na primeira metade do século XX, incluindo o aumento do acesso de estudantes judeus (o número torna-se significativo na década de 1910, apesar de testes e quotas específicos) e das mulheres (cuja proporção no número total de alunos de graduação é superior a $47 \%$ em 1920), mas o ponto de inflexão essencial é a chamada lei do GI Bill de 1944, que garante aos excombatentes um ano de ensino superior gratuito por cada período de 3 meses passados no exército, sendo que o Estado pode financiar até 48 meses de formação. A lei determina que as taxas de inscrição e outras taxas, bem como a compra de livros e material escolar por uma quantia total máxima de US\$ 500 por ano, são pagas diretamente para o college ou a universidade (numa época em que as taxas de inscrição têm um valor médio de US\$ 300 nas instituições privadas e são consideravelmente mais baixos nas universidades estaduais). $O$ aluno também recebe uma indemnização de subsistência. O sucesso da lei foi imediato: em 1946, as matrículas na universidade, feitas a partir do quadro fixado por essa lei, ultrapassaram 1 milhão, e os pagamentos do governo federal somaram mais de US\$ 5,5 bilhões. Em 1950, dos 14 milhões de excombatentes elegíveis, mais de dois milhões optaram por prosseguir os estudos superiores.

18 O GI Bill é uma grande inovação na história da educação superior americana por várias razões: em primeiro lugar, esta lei faz com que a possibilidade de levar estudos superiores seja um direito, e não apenas um privilégio. Em outras palavras, não há limite para o número de beneficiários. Além disso, este direito concedido ao estudante é transferível: um veterano pode candidatar-se para entrar em Harvard, mas também num community college perto de sua casa, ou numa faculdade de direito ou de medicina, ou ainda numa escola de engenharia. Para prevenir qualquer tipo de abuso do sistema, a instituição deve ser reconhecida pelo governo federal, e portanto uma consequência indireta do GI Bill é é a criação de um sistema de avaliação das universidades. Preocupadas em manter a sua independência em relação ao governo federal, e em conformidade com a Décima Emenda da Constituição americana, segundo a qual "os poderes não delegados aos Estados Unidos pela Constituição, nem proibidos por ela aos Estados, são reservados a estes respectivamente, ou ao povo", as universidades se submetem voluntariamente aos organismos de avaliação independentes. É o início do sistema de acreditação regional, com seu ciclo de avaliação institucional a cada dez anos, que gradualmente se torna o procedimento padrão para todas as instituições que concedem diploma, especialmente se estas desejam ser elegíveis aos financiamentos federais. Outra mudança trazida pela lei GI Bill reside na maneira pela qual as universidades e faculdades avaliam candidaturas de estudantes prospectivos: com o novo fluxo de pedidos, a decisão de admissão deve agora ser feita rapidamente. A tomada de decisão, aliás, é muito difícil, já que os ex-combatentes, muitas vezes, não têm os mesmos históricos escolares do que os alunos convencionais. Daí se elabora um sistema de admissão que recorre, cada vez mais, aos testes padronizados e toma também em conta a experiência adquirida fora do ensino médio. 

física das universidades que rapidamente constroem novos edifícios para as aulas, o alojamento universitário, os laboratórios e as instalações desportivas, e que devem também adaptar suas instalações para as necessidades específicas dos alunos veteranos, por vezes deficientes. Igualmente surpreendente para o observador contemporâneo, é a transformação da cultura estudantil devido à chegada maciça da nova geração: mais velhos do que o estudante tradicional que tem entre 17 a 21 , os alunos que chegam à universidade através do GI Bill também realizam estudos mais pragmáticos e por isso as universidades fazem muitos esforços para diversificar a sua gama de cursos, a fim de responder a esse desejo de adquirir uma formação que dê rapidamente acesso a um bom trabalho, num período pós-guerra em plena expansão econômica. Por fim, após os avanços das últimas décadas no que diz respeito à igualdade de gênero, as matrículas dos antigos combatentes correspondem com uma masculinização do campus (embora, nesses ex-combatentes, cerca de 60.000 mulheres também se beneficiem dos programas de estudos). É preciso esperar a década de 1970 para que as mulheres representem novamente $40 \%$ dos alunos de graduação no país. Atualmente, essa proporção é de $55 \%$.

O impacto considerável do GI Bill não deve, contudo, ser exagerado, pois ele tem uma limitação crucial: sua fraca influência sobre as relações raciais nas faculdades e universidades. Certamente, os GI negros eram elegíveis e o número de estudantes afroamericanos aumentou significativamente graças a este dispositivo, mas os termos da legislação não incluem, para as instituições participantes, qualquer obrigação de evitar a discriminação. As instituições que tinham excluído, tradicionalmente, as minorias raciais, continuaram a fazê-lo impunemente (o governo federal praticou até 1948 a segregação nas forças armadas). Apesar dos avanços democráticos do GI Bill, a doutrina "separados mas iguais" continuou a nortear as relações raciais na universidade e em outras instituições americanas. Esta situação perdura até a aprovação pelo Congresso do grande Ato dos Direitos Civis de 1964: este proibe a segregação e a discriminação que ainda eram praticadas apesar da decisão, em 1954, do Supremo Tribunal Federal Brown contra o Conselho de Educação de Topeka, no Kansas.

O GI Bill, não deixa de ser a primeira etapa na constituição de um novo papel para o governo federal no ensino superior, que tem uma importância crescente até hoje. Já em 1947, o presidente Harry Truman ordenou a elaboração de um estudo, que foi publicado sob o título Higher Education for American Democracy. Esse estudo destaca a importância nacional do ensino superior no novo contexto da Guerra Fria, tanto para as questões sociais como no que diz respeito à influência dos Estados Unidos no mundo e à defesa do país. Após 65 anos, esta visão quase não mudou; ela até foi reforçada, com o crescimento espetacular das universidades americanas desde a Segunda Guerra Mundial.

Após a Segunda Guerra Mundial, o ensino superior americano, de fato, beneficiou de trinta gloriosos anos de prosperidade, de prestígio e de popularidade. 0 governo federal continuou desenvolvendo uma política de financiamento da pesquisa científica, cuja importância foi considerada como estratégica para o país, e que teve um primeiro impulso com o Projeto Manhattan, elaborado durante a guerra para a fabricação da bomba atômica. Ele começou a financiar programas de pesquisa e de formação em línguas estrangeiras, cobrindo diferentes áreas culturais, e assinou contratos de pesquisa com um grande grupo de universidades do país, encarregadas da realização de várias missões de pesquisa aplicada. Devemos lembrar que este dinheiro federal nunca 
substitui as contribuições financeiras dos estados federados, que são os principais órgãos governamentais responsáveis pelos negócios e pelo financiamento educativos, em todos os níveis. No entanto, é inegável que os financiamentos federais rapidamente tornam-se indispensáveis para o funcionamento, a expansão e a reputação das instituições beneficiárias desses contratos; da mesma forma, a grande maioria das universidades e dos colleges que não beneficiam desses financiamentos encontram-se na obrigação de buscar outras fontes de financiamento e outros meios que lhes permitam diferenciar-se de seus concorrentes, com o objetivo de atrair estudantes em números cada vez maiores... mas cada vez mais determinados em escolher sua universidade em função de seus interesses e de suas necessidades próprias. Além de oferecer um nível sem precedentes de financiamento na história do ensino superior, este novo envolvimento do governo federal também tem o efeito de aumentar a competição entre as escolas e de fazer com que todas as escolas desenvolvam um nicho, uma identidade única.

Paralelamente a este papel do financiamento das pesquisas, impulsionado por razões de interesse nacional, o governo federal reconhece a dupla necessidade de abrir o ensino superior a uma maior proporção da população (podemos mencionar uma grande lei sobre o ensino superior, em 1965, que cria bolsas para estudantes) e de possuir instituições que tenham a capacidade de ser reconhecidas internacionalmente pela excelência de suas pesquisas e de sua formação. $O$ panorama universitário do pósguerra, que já era rico, torna-se ainda mais forte com o aumento do número de community colleges, ou seja de instituições de proximidade que oferecem uma formação semiprofissional a um custo bastante razoável. Assim, amplia-se a base do sistema, enquanto o topo da pirâmide continua a elevar-se, graças à capacidade demonstrada dos colleges e das universidades em desenvolver programas seletivos avançados em todos os níveis, sendo que a seleção é apresentada como uma garantia de qualidade. Entretanto, é também o período em que aparece um novo tipo de instituição: os estabelecimentos privados, com fins lucrativos, de formação especializada ou profissional, e as chamadas universidades corporativas, criadas por iniciativas de grandes empresas.

Esta idade de ouro, cujo alicerce é a democratização do ensino superior e a importância da universidade de pesquisa, cria as bases para a reputação, ainda hoje, do modelo de ensino superior americano. Outro fator, certamente, é a capacidade do sistema para adaptar-se ao duplo desafio de massa causado pelo baby boom (que passou de menos de 1,5 milhões de estudantes antes da Segunda Guerra Mundial a 7,9 milhões em 1970) e pelas reivindicações dos movimentos identitários dos anos 1960 e 1970 (em especial as reivindicações das minorias etnorraciais e sexuais) que transformaram profundamente a instituição universitária.

$\mathrm{Na}$ verdade, a estrutura do ensino superior americano mudou pouco desde os anos 1970, apesar de novos desafios que surgiram com a crise econômica de 2008, a qual reduziu significativamente os recursos disponíveis para o ensino superior (e a educação em geral) nos orçamentos do Estado federal e dos Estados federados, causando ao mesmo tempo um novo aumento dos direitos de inscrição. Isto coloca o ensino superior fora do alcance de uma proporção crescente da população. Essas perigosas ameaças à democratização do acesso ao ensino superior levantam um questionamento, que nas décadas passadas teria sido inimaginável: trata-se de uma interrogação sobre os limites do modelo norteamericano e sobre sua sustentabilidade. É neste contexto que se deve 
interpretar o recente apelo do Presidente Obama para dar um novo impulso aoo desenvolvimento da educação superior americana, apostando menos na excelência das instituições de elite como motor do sistema, e mais nos community colleges. ${ }^{10}$

Para ter uma noção do interesse em reorientar as prioridades nacionais, é preciso salientar que a população estudante dos EUA elevou-se, em 2010, a 19,1 milhões de pessoas (contra 13,8 milhões em 1990), o que representou mais de $41 \%$ da faixa etária de 18-24 anos, distribuídos em 4352 instituições onde o custo da educação mais do que duplicou desde 1990 (em 2010, o custo médio anual das taxas de inscrição e alojamento nos colleges e nas universidades públicas era de pouco menos de 15 mil dólares, contra pouco mais de 40 mil nas instituições privadas). Sem dúvida, muitos outros países podem também meidtar sobre essa lição...

Paradoxalmente, o desenvolvimento de sistemas de avaliação padronizados remonta a 1945, com o GI Bill, que foi uma alavanca para a democratização do ensino superior: a racionalização foi imposta para lidar com o crescimento numérico dos estudantes e controlar o fluxo de fundos públicos. No fundo, já nos primórdios, o sistema de ensino superior norte-americano funciona em várias velocidades e baseia-se na multiplicação de instituições especializadas (seja nas universidades ou nos departamentos de pesquisa) para integrar os diferentes setores da população. Os leitores desse número da revista serão capazes de compreender o desenvolvimento dos departamentos de "Black Studies" nos Estados Unidos na década de 1960 graças ao artigo de Caroline Rolland, enquanto Ramón Grosfoguel analisa os dilemas atuais dos departamentos de estudos étnicos. São dilemas que as universidades indígenas no México (artigo de David Lehmann) e na Bolívia (artigo de Anders Burman) compartilham em grande parte. Apesar de uma história universitária diferente, com raízes na Espanha medieval.

\section{O sistema de ensino universitário da América Latina na encruzilhada dos modelos europeus e norte- americanos}

Alguns grandes marcos históricos ${ }^{11}$ merecem ser destacados para a comparação com o processo norteamericano. Antes de 1492, instituições especializadas na formação acadêmica das elites podem ser identificadas nas fontes relativas aos impérios asteca $\mathrm{e}$ inca. Com a conquista espanhola, o modelo da universidade medieval e escolástica, encarnado na Espanha por Salamanca (Studium Generale, 1218) e Alcala de Henares (Estudio de Escuelas Generales, 1293), se espalha, com algumas adaptações. Inicialmente, os cursos são ministrados no claustro da catedral e em casas qua as instituições alugam à cidade. No início do século XV, foram construídos colégios (edifícios que incluem um internato para os alunos pobres e bolsistas, bem como salas de aula e espaços para a vida social, cultural e esportiva). Os colégios menores preparam para o bachiller (bacharel) e os colégios maiores dispensam aulas de licenciatura e de doutorado, mas os exames ocorrem na universidade. Com o tempo, os colégios são monopolizados pela nobreza. A influência de Salamanca é particularmente visível em Lima (1575) e na Cidade do México (1595), através da adoção de seus métodos de organização, de seus programas, práticas e privilégios, assim como do movimento dos professores. Lima e a Cidade do México começam a competir para exercer influência sobre outras universidades regionais. A maioria das universidades recebem autorizações tanto reais como pontifícias. Frequentemente, elas são associadas com 
seminários, conventos e colégios dominicanos, agostinianos ou jesuítas ${ }^{12}$. Algumas universidades são ditas mayores, oficiales y generales, com rendas da Real Hacienda, com muitas cadeiras e privilégios; outras são ditas particulares e não têm a mesma autoridade para emitir diplomas. Elas são organizadas em quatro faculdades mayores (grandes faculdades): teologia, direito canônico, direito, medicina, junto com uma faculdade menor de "arte e filosofia". Um colégio francsicano, Santa Cruz de Tlatelolco, foi criado muito cado para as elites indígenas do México (1533): durante cinquenta anos, o ensino do latim, mas também o desenvolvimento de um alfabeto latino para o Nahuatl, deram à luz vários trabalhos científicos importantes com base nos conhecimentos médicos e históricos nahua. As primeiras gerações de nativos formados na escola tinham responsabilidades significativas, tanto na sua própria universidade como em outras instituições coloniais, mas depois esse modelo definhou. Este modelo difusionista, que se fundamenta na importação do modelo medieval espanhol, é bastante simplista, e no entanto favorece um processo importante: a fundação rápida e sustentável de mais de vinte e cinco universidades em todo o território da América espanhola, enquanto a coroa Portuguesa, no mesmo período, permitiu apenas a abertura de colégios e não de universidades. Até 1808, data em que a família real instalou-se no Brasil, não havia no solo dessa colônia nenhuma universidade.

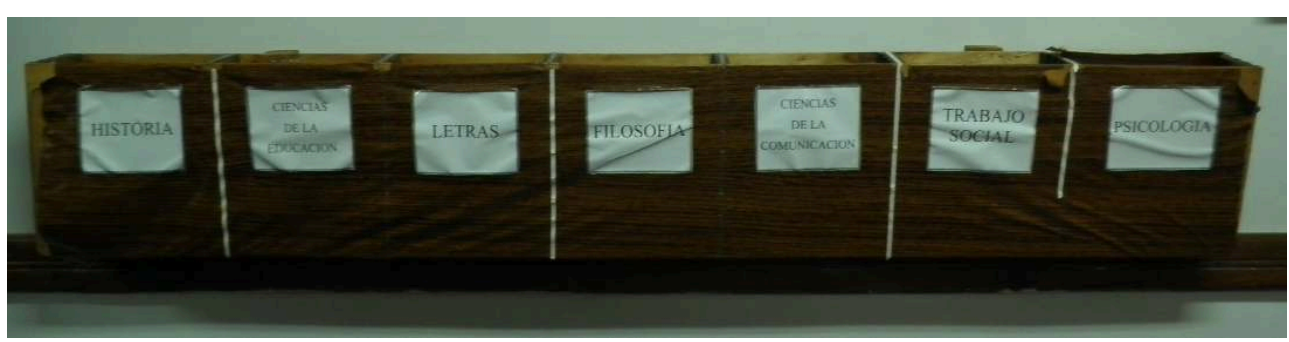

Caixas de correio dos sete departamentos na faculdade de Filosofia da Universidade Nacional de Assunção

Um aspecto concreto da história da construção dos saberes: as caixas de correio dos sete departamentos na faculdade de Filosofia da Universidade Nacional de Assunção.

Foto: C. Boidin, Paraguai 2011

O vento do Iluminismo francês, no final do período colonial, também soprou fortemente nas universidades latino-americanas, antes que o período das independências republicanas difunda os princípios de organização napoleônica (longas carreiras profissionais de 6 a 7 anos, sem diplomas intermediários), assim como o princípio, inspirado por von Humboldt, da integração do ensino à pesquisa, que tem o primado. $O$ positivismo de Comte também teve um impacto significativo, seja do lado espanhol ou português. No século XX, como o sublinha o artigo de Olivier de Guadalupe, três períodos são importantes. Em primeiro lugar, a reforma de Córdoba, em 1918, que defendeu o princípio da gratuidade do ensino e a luta pela democratização de uma instituição concebida como pública e independente. A reforma da década de 1970 levou ao crescimento de diferentes instituições de ensino superior que não são necessariamente do tipo acadêmico, mas que permitem abrir o sistema público. A terceira reforma se acelera após a década de 1990, com a massificação, a privatização e a internacionalização da educação superior na América Latina. 


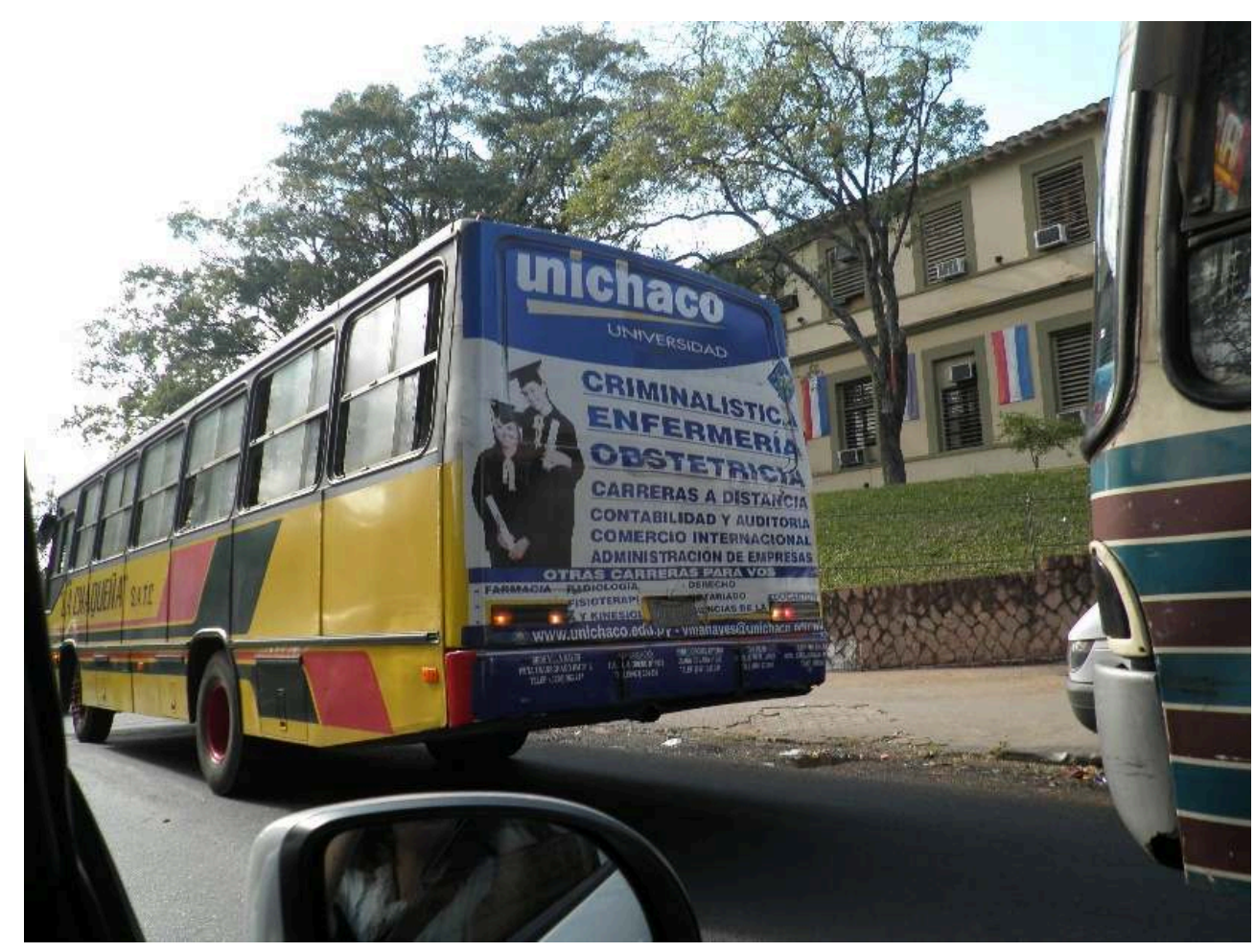

Propagandas para as universidades privadas na América Latina. Assunção, Paraguai

Multiplicação de propagandas para as universidades privadas na América Latina. Assunção, Paraguai, em 2011

Foto: C. Boidin 2011

\section{Massificação, privatização e desenvolvimento das universidades indígenas no Ensino Superior na América Latina}

Dois tipos diferentes de análises se opõem: uma, com base numa longa tradição de pensamento crítico na América Latina, decifra as políticas neoliberais contemporâneas ${ }^{13}$, enquanto a outra multiplica os relatórios sintéticos para justificar suas "recomendações" sobre as reformas (Banco Mundial, Fundo Monetário Internacional, em particular). Mas antes, alguns dados sobre a massificação e a privatização acelerada do sistema do Ensino Superior da América Latina ${ }^{14}$ :

31 Número de universidades e instituições de ensino superior (IES) na América Latina

195075 Universidades

1975330 Universidades

1985450 Universidades

1995812 Universidades (60,7\% privadas) 5438 IES

20021.213 Universidades ( $69,2 \%$ privadas) 7514 IES

Hoje: provavelmente mais de 2.000 universidades.

32 Número de alunos inscritos no sistema de ensino superior na América Latina,
$1950 \quad 267000$
19701640000
19804930000
19907350000 
200011500000

200515293181

200917757000

Hoje (2012), cerca de 18 milhões.

Atualmente, o Brasil conta com 5.95 milhões de estudantes matriculados ${ }^{15}$, o México e a Argentina teriam, cada um, cerca de 2,5 milhões de estudantes. Os três países são responsáveis por cerca de 11 milhões de inscritos, ou 60\% dos 18 milhões de estudantes latino-americanos hoje. Estes são também os três países com o número mais consistente de estudantes em programas de Mestrado e Doutorado. Considerando o número total de alunos, seguem a Colômbia (1,3 milhões), a Venezuela (1 milhão), o Peru (900.000), o Chile (670.000), Cuba (470.000), a Bolívia (350.000). A taxa de matrícula no ensino superior da América Latina melhorou significativamente de $17 \%$ no início da década de 1990 para 34\% hoje. A situação varia consideravelmente de país para país: $18 \%$ na Guatemala, 27\% no México, 30\% no Brasil, 32\% na Colômbia, 35\% no Peru, 52\% na Venezuela, 67\% na Argentina e até $88 \%$ em Cuba. Em outras palavras, enquanto o México e a Argentina têm o mesmo número de alunos, o México está longe de responder, tanto quanto a Argentina, às expectativas de seu povo. Além disso, alguns sistemas educacionais são particularmente desiguais: as famílias com baixos recursos econômicos são excluídas das universidades públicas de qualidade, já que não podiam enviar seus filhos para boas escolas secundárias (públicas ou privadas). Este é particularmente o caso do Brasil, e também do México, do Chile e do Equador. Hoje, o investimento global anual por aluno, na América Latina, é de 2.380 dólares. Em outras palavras, considerando o número total de estudantes, as estatísticas da América Latina e dos Estados Unidos são muito parecidas (18 milhões contra 19 milhões), mas a grande diferença é que os estudantes da América Latina são consideravelmente menos financiados (lembremos que a taxa de inscrição nos Estados Unidos varia de 15.000 a 40.000 dólares anuais).

Esta massificação, qualificada por alguns como uma democratização, não poderia ter ocorrido sem a proliferação de universidades privadas, que elas não tenham fins lucrativos ou que elas sejam, ao contrário, claramente orientadas para captar o investimento na educação que as famílias latino-americanas estão dispostas, cada vez mais, a realizar para seus filhos. Além disso, os processos de integração nas Américas suscitaram a criação de associações entre diferentes instituições de ensino superior, públicas ou privadas, de países distintos (artigo de Guadalupe Olivier, neste dossiê) ${ }^{16}$, assim como uma proliferação de relatórios comparativos. 


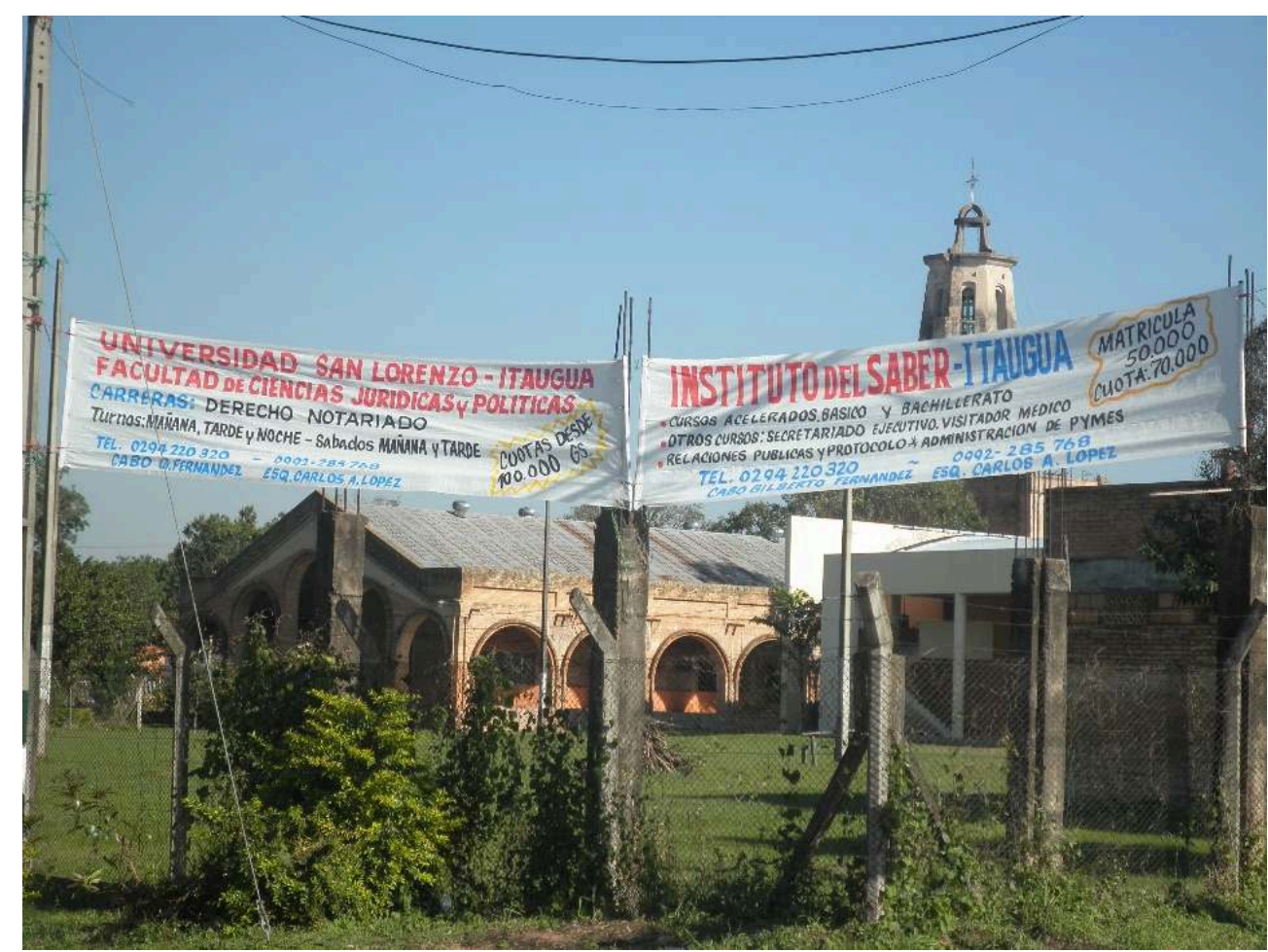

Publicicades em San Lorenzo, no Paraguai

Publicidade para a Universidade, de um lado, e para um "Instituto de Conhecimento", do outro, em San Lorenzo, no Paraguai.

Foto: C. Boidin 2011

Desde 1960, vários organismos da UNESCO, bem como a CEPAL (a Comisião Econômica para a América Latina e o Caribe), têm impulsionado estudos comparativos dos sistemas de ensino na América Latina. Em 1978, o Centro Regional para a Educação Superiora na América Latina e o Caribe (CRESALC), que mudou de nome no final de 1990 e chegou a ser o Instituto Internacional para a Educação Superior na América Latina e o Caribe (IESALC), tem produzido muitos relatórios como o chamado Documento de Política para el Cambio y el Desarrollo de la Educación Superior, em 1995. Este relatório levou a UNESCO, em 1998, a definir um plano de ação organizado em torno de cinco critérios: 1) a relevância social da educação, 2 ) a qualidade, a avaliação, 3) a gestão e o financiamento, 4) a utilização de novos meios de comunicação, 5) a cooperação internacional. Estas cinco áreas fazem pensar, de imediato, naquelas que a União Europeia tinha estabelecido em 1999, com a diferença de que a dimensão social da aprendizagem é destacada como uma prioridade, antes mesmo da vontade de avaliação.

Finalmente, alguns anos antes da Europa, vários países da América Latina liberalizaram boa parte de seus sistemas de ensino superior e implementaram a avaliação padronizada da pesquisa e da educação. Ao mesmo tempo, as instituições destinadas prioriariamente aos povos indígenas aumentaram: são as chamadas universidades "indígenas" ou "interculturais" - o nome varia conforme os países e os períodos -, a propósito das quais refletem Anders Burman, focando-se na Bolívia, assim como David Lehmann, no caso do México. 


\section{Desprovincializar as universidades europeias}

37 Na França, a reforma das universidades, elaborada a todo vapor em 2007, levantou um clamor e reuniu nas ruas manifestantes de todo o espectro político, tanto na esquerda como na direita. A determinação em defender uma certa ideia do conhecimento científico e do ensino superior, considerando-os como "bens coletivos e públicos" e não como "bem de consumo pessoal" (um diploma válido e útil para a carreira do indivíduo), era também compartilhada tanto pelas ciências humanas e sociais como pelas ciências jurídicas, pelas ciências físicas e naturais, pelas matemáticas. Passar de uma relação pedagógica para uma relação de mercado em que o aluno se torna um cliente é algo que opõe-se à cultura acadêmica europeia. Mas na opinião pública, esta forma de defesa poderia ser vista como uma recusa, por parte dos estudiosos, em preparar seus alunos para a integração no mundo profissional. No entanto, não se trata de reagir contra a integração profissional dos estudantes: uma formação rigorosa aguça o pensamento crítico e a autonomia dos alunos, preparando-os assim a se adaptarem inteligentemente a qualquer situação social ou profissional. Tratava-se, então, de reagir contra a importação de uma cultura empreendedora dentro da universidade, contra a transformação da universidade em empresa.

Finalmente, esta série de mal-entendidos e confusões nos leva a perguntar se a origem da crise das universidades francesas, e de forma mais ampla europeias, não remonta a fatores que vão muito além das pressões geradas pelo processo de Bolonha. Esta crise sucederia, também, por conta do enfraquecimento do modelo de universidade e do universalismo procedente do Iluminismo. De fato, as críticas internas ao conhecimento e à maneira de praticar o conhecimento nas universidades não são novas (Foucault, Bourdieu, Lyotard, Latour, Rancière e outros ...). No entanto, ao longo dos últimos dez anos, o modelo universitário inspirado por Kant e Humboldt ("a ciência para e pela ciência", separada da teologia; o caráter enciclopédico das pesquisas; as figuras do professor pesquisador e do aluno pesquisador) foi também amplamente questionado e criticado pelos pensadores pós-coloniais asiáticos, latino-americanos, norteamericanos e europeus. Em particular, os autores latinoamericanos, que preferem se auto-qualificar como não-coloniais em vez de pós-coloniais, apontam para o eurocentrismo epistêmico que orienta algumas práticas da instituição. Eles denunciam o eurocentrismo, o racismo e o sexismo epistêmicos de instituições nas quais as ideias consideradas como capazes de universalidade são apenas aquelas desenvolvidas a partir de tradições ocidentais e publicadas por homens europeus ou euroamericanos. Mais profundamente, eles questionam a aspiração para um saber enciclopédico total, em particular no plano da antropologia; pois esta, embora se refira a um processo de conhecimento dos "outros", não leva ao pleno reconhecimento desses "outros" como sujeitos e autores. No entanto, essa crítica não conduz necessariamente a um relativismo forte e ao abandono de qualquer busca de universalidade. Ao contrário, o interesse das últimas reflexões propostas pelos pensadores pós-coloniais latinoamericanos reside no fato de que apontam para a necessidade de um processo de reflexão universal, elaborado através do diálogo entre pesquisadores que vêm de diferentes horizontes epistêmicos.

As reformas propostas pelo Processo de Bolonha não enfrentam precisamente estas críticas profundas. Ao contrário, concentrando-se principalmente nos métodos de gestão e de avaliação dos professores e dos diplomas, reforçam o desencanto do mundo universitário. Contudo, o potencial de renovação das universidades europeias e 
francesas é considerável. Em particular, trata-se de abrir-se mais decisivamente para os diálogos interepistêmicos, tentando construir uma nova ecologia de saberes. Longe de pregar um relativismo inconsistente ou de construir "historietas", o objetivo consistiria em buscar o conhecimento universal, mas através do estabelecimento de um diálogo horizontal entre diferentes tradições de pensamento.

Reformar a universidade à procura de um universalismo menos provincial e mais aberto implica uma profunda revisão de nossas maneiras de pensar e das delimitações que existem entre as disciplinas. A criação do campus Condorcet poderia ser uma oportunidade de buscar formas de pensar multiversais e de manter a universidade ligada com as questões cruciais de sociedade ${ }^{17}$. Estas aberturas e novas construções dos saberes se tornariam visíveis através da arquitetura escolhida para este campus. As conversas com Cynthia Ghorra-Gobin e João Sette Whiteker Ferreira sobre a organização dos campi californianos e brasileiros, respectivamente, permitirão apreender, por contraste, as especificidades de um campus localizado no norte de Paris e aberto à vida de bairros de classe média, em plena reconstrução, nas cidades de Aubervilliers e Saint Denis.

41 É nesse sentido que este dossiê (junto com a conversa sobre o campus Condorcet que está incluida nele) propõe um diálogo com outras tradições de pensamento, particularmente latino-americanas, com experiências tais como as universidades indígenas. De fato, se as "corporate universities" nos Estados Unidos são consideradas como um modelo a partir de 1970, a América Latina vai rapidamente seguir esta pauta e multiplicar esse tipo de experiências na década de 1980, durante a qual universidades autônomas e indígenas começam a se constituirem. Em outras palavras, a análise das transformações que atravessou a universidade, tanto no continente americano durante as quatro últimas décadas, como na Europa ao longo dos últimos dez anos, deverá ajudar-nos a compreender melhor a situação que estamos passando e a refletir sobre a universidade europeia de amanhã.

\section{NOTAS}

1. Nós brincamos aqui com o sentido que Dipesh Chakrabarty dá à expressão Provincialiser l'Europe - La pensée postcoloniale et la différence historique, Paris, Edições Amsterdam, 2009, tradução de Olivier Ruchet e Nicolas Vieillescazes. Para Dipesh Chakrabarty, que reflite sobre a situação indiana, "o pensamento europeu é tão indispensável quanto inadequado para pensar na experiência da modernidade política nas nações não-ocidentais, e provincializar a Europa tornase uma tarefa que consiste em examinar a maneira pela qual é possível renovar este pensamento, o qual constitue, atualmente, nossa herança comum e que afeta a todos nós, a partir das margens e para elas. Mas as margens são, evidentemente, tão plurais e diversas quanto os centros." (p. 53). Para nós que pensamos desde a Europa, desprovincializar as universidades europeias consiste em reconhecer, humildemente, a necessidade vital de "ficar ligados", de deixar-se renovar pelas tradições dos pensamentos mais diversos. Nós o explicitamos mais detalhadamente no final desta edição. 
2. Para uma classificação das universidades latinoamericanas entre elas: http://americalatina.blog.lemonde.fr/2011/10/05/l'universite-de-sao-paulo-en-tete-du-premier-classementlatino-americain/

3. http://www.cpihts.com/PDF/Declaracao\%20de\%20la\%20Sorbonne.pdf consultado no dia 2 de junho de 2012.

4. http://eacea.ec.europa.eu/education/eurydice/documents/thematic_reports/122FR.pdf

5. Isabelle Bruno, "Y a-t-il un pilote dans l'Union ? Tableaux de bord, indicateurs, cibles chiffrées : les balises de la décision ", Politix, vol. 82, n², 2008, p. 95-118.

6. Comunicado de Londres, 2007, p. 5, citado no relatório da Comissão Europeia, La modernisation de l'enseignement supérieur en Europe : financement et dimension sociale, 2011, p. 9.

7. (Generalização dos cursos em três fases, Licenciatura, Mestrado e Doutorado, com a capitalização de ECTS (créditos) ao longo do percurso universitário, qualquer que seja a universidade e a região).

8. Embora não fosse inteiramente nova, já que, por exemplo, a Free University of New York foi fundada em 1847, a tendência se acelerou depois da Guerra Civil, com o nascimento da universidade de Cincinnati, da Hunter College, em Nova York, da Wayne University, em Detroit, da Boston University, da Temple University, na Filadélfia, e da George Washington University, em Washington.

9. A este respeito, as novas universidades públicas desempenham um papel de liderança, em primeiro lugar com a Universidade de Iowa (1855) e a de Wisconsin (1863), seguidas pelas universidades de Indiana, Missouri, Michigan e Califórnia na década de 1870. A partir desta década, a maioria das instituições de ensino superior no Oeste e Meio-Oeste aceitam esta prática, e as resistências emergem principalmente nas universidades da "Ivy League" do Nordeste.

10. Como o sublinha Dominique Godrèche: "acessíveis a todos, independentemente da idade, da origem social ou da proveniência acadêmica, os community colleges representam nos Estados Unidos o remédio para um ensino tão caro quanto seletivo. A formação de dois anos prepara os alunos, ao sair da escola, para o associate's degree, necessário para obter - depois de dois anos na Universidade - o bachelor's degree (equivalente da Licenciatura). Assim, oferece aos estudantes das classes menos favorecidas, que não podem pagar quatro anos de estudo numa universidade privada, o acesso ao ensino superior. Além disso, essas faculdades oferecem cursos de formação profissional, sancionados por um título e uma com uma educação diversificada, a um segmento da população que de outra forma não teria direito a qualquer coisa, inclusive os imigrantes. [...] As grandes forças dos community colleges são sua capacidade de integração no tecido económico da região, assim como a presteza que eles demonstram para adaptar os cursos às novas necessidades. "Ver Dominique Godrèche, "En marge des universités, les community colleges" e "Onze millions d'étudiants", Le Monde Diplomatique, Junho de 2010.

11. Para uma primeira leitura sobre essa questão: Celina Lértora Mendoza, "Lineamientos para uma historia de la universidad latinoamericana" Cuadernos de la Facultad de Humanidades y Ciencias Sociales, diciembre, 15, pp.43-51. Para ir mais longe: Diana Soto Arango, Manuel Lucena Salmoral y Carlos Rincón (ed.), Estudios sobre la universidad latino-americana. De la colonia al siglo XXI, RUDECOLOMBIA, HISULA, Universidade Pedagógica y tecnológica de Colômbia, Ed. Doce Calles 2003.

12. Ver Aguedas Rodriguez Cruz, la proyección de la Universidad de Salamanca, en Hispanoamérica, sem data, pós-2000, disponível em http: //www.americanistas.es/biblo/textos/s04/s 04-10.pdf; La Universidad en la América Hispánica, Madrid, Mapfre, 1992.

13. Ver em particular os trabalhos de Mollis, M. (comp.), Las universidades en América latina: reformadas o alteradas?, Buenos Aires, CLACSO, 2003.

14. Francisco Lopez Segrera, "La educacion superior en el mundo y en América latina y el Caribe ", Revista paraguaya de sociologia, ano 47, no 136, janeiro-junho 2010. Lopez Segrera é uma das principais referências para seus relatórios UNESCO no ensino superior na América Latina 
desde a década de 2000. Quando os números abaixo não vêm de seu artigo, o precisaremos rigorosamente.

15. http://gestao2010.mec.gov.br/indicadores/chart_60.php dados fornecidos pelo Ministério da Educação brasileiro (MEC).

16. http://america-latina.blog.lemonde.fr/2011/10/05/l'universite-de-sao-paulo-en-tete-dupremier-classement-latino-americain/

17. No programa científico do Campus, estes princípios são precisados: "Reunir as ciências humanas e sociais; juntar o estudo do passado ao estudo do presente; promover os questionamentos transversais, adaptados para a análise da dinâmica de um mundo global. Estes princípios são ligados a duas orientações: uma voltada par os objetos (as áreas culturais, as religiões, os textos, os territórios, as populações, etc), que têm o primado sobre as disciplinas; e a outra voltada para a criação de uma ferramenta de perícia e de compreensão do contemporâneo, junto com um objetivo de ampliação e de renovação das perspectivas nas ciências humanas e sociais. " http://www.campus-condorcet.fr/campus-condorcet/La-politique-scientifique/Leprogramme-scientifique/p-451-Le-programme-scientifique.html

\section{AUTORES}

\section{CAROLINE ROLLAND-DIAMOND}

Maître de conférences en histoire à l'Université Paris Ouest Nanterre. Ses axes de recherche portent sur l'histoire sociale, l'histoire politique et l'histoire urbaine des États-Unis au XXe siècle, ainsi que sur l'histoire des mouvements étudiants américains depuis les années 1960, l'histoire de l'institution universitaire, la théorie des mouvements sociaux et l'histoire de la répression politique. Elle est l'auteur de Chicago : le moment 68. Territoires de la contestation étudiante et répression politique (Paris: Syllepse, 2011) et a co-dirigé (avec Robi Morder) Etudiant(e)s du monde en mouvement. Migrations. Cosmopolitisme et internationales étudiantes (Paris, Syllepse, 2012).

rolland.caroline@gmail.com

\section{CAPUCINE BOIDIN}

Maître de conférences en anthropologie à l'Université Sorbonne Nouvelle Paris 3, IHEAL (Institut des Hautes Etudes d'Amérique Latine). Chargée de cours de guarani à l'INALCO (Institut National des Langues et Civilisations Orientales), ses axes de recherche portent sur le métissage, le genre, les mémoires de guerre. Elle a publié en 2010 un numéro des Cahiers des Amériques latines sur le tournant décolonial.

http://www.ladocumentationfrancaise.fr/catalogue/3303332400621/index.shtml; http:// www.iheal.univ-paris3.fr/spip.php?article1041

\section{JAMES COHEN}

Professeur à l'Institut du monde anglophone et enseignant à l'Institut des hautes études de l'Amérique Latine, Université de Paris 3 Sorbonne Nouvelle. Spécialiste des questions de race/ ethnicité et d'immigration aux Etats-Unis et du rôle des Etats-Unis dans les Amériques.

jim.cohen@libertysurf.fr 


\section{RAMON GROSFOGUEL}

Maître de conférences (Associate Professor) en études ethniques à l'université de Californie, Berkeley et chercheur invité auprès de la Maison des sciences de l'homme à Paris. Il a publié de nombreux articles et ouvrages sur l'économie politique du système mondial et sur les migrations caribéennes en Europe occidentale et aux États-Unis. Grosfogu@Berkeley.edu 